\title{
Location of Pulp Chamber in Lower First Permanent Molars: In-Vitro Study
}

\author{
Abdul Qadir Khan Dall, Sarwanand, Sarwat Batool, Suraj Arora, Saifullah Qureshi, \\ Muhammad Ahmed Bari
}

\begin{abstract}
OBJECTIVE: To determine whether the pulp chamber floor of mandibular first permanent molars is always centrally located (law of centrality) at the level of cemento enamel junction (CEJ) or off-centered (mesiobuccally).

METHODOLOGY: This cross-sectional analytical study was conducted at Dental OPD Liaquat University of Medical \& Health Sciences, Jamshoro / Hyderabad from June to December 2017 with probability consecutive sampling technique. Total 384 extracted teeth were decoronated at cemento-enamel junction level and photographed. Paint milimeter grid was superimposed on photograph and position of pulp chamber was measured centered or off-centered. Inclusion Criteria was set as ages of 20 to 60 years of either gender, included extracted mandibular first permanent molar teeth of both genders with intact crown and root morphology without any restoration and dentin caries. Endodontically treated teeth, heavily restored teeth, and teeth with deep non-carious cervical lesions were excluded. The collected data was analyzed on SPSS version 16, with p-value of less than 0.05 .

RESULTS: Total $55.7 \%(n=214)$ specimens were observed to have mesiobuccal off-center location of pulp chamber and 44.7\% (170) had centrally located pulp chamber (P-value 0.007). In age-group1 (20-40 years), 140 specimens observed with centrally located pulp chamber and only 20 specimens had off-center location of pulp chamber. In age-group2 (41-60 years), 30 specimens had central location while 194 observed to have off-centered (mesiobuccally) position of pulp chamber ( $p$-value of 0.001 ).

CONCLUSION: Location of the pulp chamber of mandibular first molar is mesiobuccally off-centered in majority of specimens.

KEYWORDS: Location of Pulp Chamber, Lower first Permanent Molars.
\end{abstract}

This article may be cited as: Dall AQK, Sarwanand, Batool S, Arora S, Qureshi S, Bari MA. Location of Pulp Chamber in Lower First Permanent Molars: In-Vitro Study. J Liaquat Uni Med Health Sci. 2020;19(02):122-7. doi: 10.22442/jlumhs.201920674

\section{INTRODUCTION}

Success of endodontic therapy is dependent on comprehensive knowledge of internal anatomy of tooth in addition to essential procedural steps. These basic steps include access cavity, chemo-mechanical preparation and three-dimensional hermetic sealing of the root canal system ${ }^{1-3}$. The design of access cavity preparation is dictated by anatomy of pulp chamber (PC). Anatomy may vary not only between teeth types but also within same type of teeth. Beside this the studies have demonstrated complexities of root canal system, with varying configurations of root canal, variable sizes of PC, accessory and lateral canals ${ }^{1,4-6}$. Tooth structure conservation is also important as little over reduction of tooth substance may produce significant decrease in tooth stiffness ${ }^{6}$. During access cavity preparation endodontic mishaps like, failure to locate the canals, failure to shape, clean and irrigate the canal, ledge formation, instrument separation, increase cuspal deflection and cusp fracture which predispose to failure of root canal treatment; may be prevented by adhering to basic principles of access cavity preparation ${ }^{3,5,6}$. Cemento-enamel junction (CEJ) is the most important and reliable anatomical landmark for determination of location of $\mathrm{PC}^{7}$. The proposed law of centrality for relationship of the PC to clinical crown says that "the floor of pulp chamber always located at the center of tooth at the CEJ level"2. Some other studies also support the central position of the PC at $C E J^{8,9}$. While Mickel AK $2007^{10}$ are of the opinion that PC in mandibular first permanent molar lie more lingual position at CEJ level. But contrary to this Goodis CJ $2014^{11}$ defined in his work about the chamber of mandibular first permanent molar that PC placed below central groove, buccal-lingual groove, mesial-buccal cusp and mesial marginal ridge. All above four landmarks are located mesially over the tooth. Floor of PC is contained with anatomic landmarks which help to locate the canal orifices ${ }^{1-3}$. For the access opening of mandibular first molar (MFM), mesial boundary is in line with mesial cup tip, while distal boundary is buccal -lingual groove, and PC rarely crosses these boundaries ${ }^{1}$. Beside this clinician must focus on the floor of PC because occurrence of extra canal is always suspected in mandibular molars.

Numerous studies have shown highly variable anatomy of the MFM that needs extra attention during access opening ${ }^{3}$. MFM tooth is the most frequently 
perforated and heavily restored tooth in mandible. MFM plays important role in mastication and helps in maintaining the continuity of dental arch and vertical dimension of occlusion and maintains the position of cheeks \& tongue. Proper endodontic treatment allows preservation of these teeth and integrity in dento-facial system $^{12,13}$.

In terms of ethnic diversity of PC location, a very few studies have been conducted and mentioned in the endodontic literature. Studies suggest that ethnicity is influencing factor for anatomic variations and it should be considered during pre-operative evaluation phase of root canal therapy. Therefore, this study was conducted on MFM in Pakistani population study sample to check the alternate hypothesis; with the objective to determine the centered or off-centered (mesiobuccally) position of pulp chamber of mandibular first permanent molars at cemento enamel junction in Pakistani population sample.

\section{METHODOLOGY}

This cross-sectional analytical study was conducted at Dental OPD Liaquat University of Medical \& Health Sciences (LUMHS) Jamshoro / Hyderabad, Sindh, Pakistan from June to December 2017 with probability consecutive sampling technique. Sample size for this study was calculated through Open Epi tool sample size calculator. Given the population of 1 million (default for large population), since the frequency of location of pulp chamber mesiobuccally was unknown, hence we have taken it as $50 \%$ at confidence interval $95 \%$. We used following terms and definitions in this study.

- Pulp Chamber: It is an area of anatomic crown and trunk of root that contains pulp tissue.

- Cemento-Enamel Junction (CEJ): Area of tooth at which anatomic crown ends and anatomic root begins OR at which enamel of crown ends and cementum of root begins.

- Law of Centrality: "The floor of the pulp chamber is always located in the center of tooth at the level of CEJ". 2

- Off-Centrally: The chamber is considered offcenter when it is deviated from measured average centre of tooth to either mesially or lingually.

Inclusion Criteria was set as ages of 20 to 60 years of either gender. We included extracted mandibular first permanent molar teeth of both genders with intact crown and root morphology without any restoration and dentin caries. We excluded endodontically treated teeth, heavily restored teeth, and teeth with deep non-carious cervical lesions.

Total 384 extracted mandibular first permanent molars fulfilling inclusion criteria were included in study. Teeth were collected from dental outpatient department (OPD) of Liaquat University Medical and Health Sciences Jamshoro, Liaquat university hospital
Hyderabad and private clinics of Hyderabad, Sindh, Pakistan. Patients were consented for their extracted tooth to be used for research purpose, and a written consent form was got signed by every patient. Extracted teeth were cleaned with cotton and disinfected in sodium hypochlorite solution for 24 hours and stored in normal saline. All teeth were then molded in soft plaster perpendicular to horizontal axis. Teeth were cut at cemento-enamel junction level with high-speed hand piece using diamond disc. Pulp chamber of every tooth was irrigated and cleaned using sodium hypochlorite solution. Photographs of each tooth were taken with camera (Canon IXUS 135, 16.0 Mega Pixels) after sectioning the tooth. Then photographs were transferred to computer, by using 'Paint', all photographs were individually superimposed on $1 \mathrm{~mm}$ grid and ruler. Measurements from outer wall of tooth to pulp chamber wall were taken and average center was calculated and position of pulp chamber was observed whether it is centrally placed or off-centered mesiobuccally. The collected data was analyzed on Statistical Package Social Sciences (SPSS) version 16, with p-value of less than 0.05 , which is significant. Frequencies and percentage were analyzed in male and female genders. The chi-square test was applied on following variables: Age Group (20-40years, 41-60years), Gender (male and female), and location of PC (centrally and mesiobuccally off-centrally placed).

\section{RESULTS}

Results were based on average measurements taken on photographs using millimeter-guiding grid over photographs. Centrally, located PC on average measurements (Figure I) and mesiobuccally offcentrally positioned PC (Figure II).

Total 384 specimens were collected, out of which, $57.3 \%(n=220)$ of data were collected from males and $42.71 \% \quad(n=164)$ were collected from females. In males, 84 teeth had centrally located and 136 teeth had mesiobuccally off-center position of PC. In females, 86 teeth had central location and 78 had off-center location of PC, these values were observed with significant $P$-value of 0.007 (Table I). Mesiobuccally off-centered pulp chamber location was observed in $55.7 \%(n=214)$ specimens while $44.7 \%$ (170) were centrally located PC.

Regarding two age groups, 160 teeth were from patients with age range from 20 to 40 years (Age group1) and 224 teeth were from patients with age range from 41 to 60 years (Age group 2). In Age group 1, 140 specimens were observed with centrally located PC and 20 specimens had mesiobuccally off-center location of PC. In age group 2, 30 specimens had center location of PC and 194 were observed to have mesiobuccally off-center position of PC, with significant p-value of 0.001 . 
FIGURE I: CENTRALLY LOCATED PULP CHAMBER

$B^{*}$ (Buccal), $D^{*}$ (Distal), L* (Lingual), $M^{*}$ (Mesial)

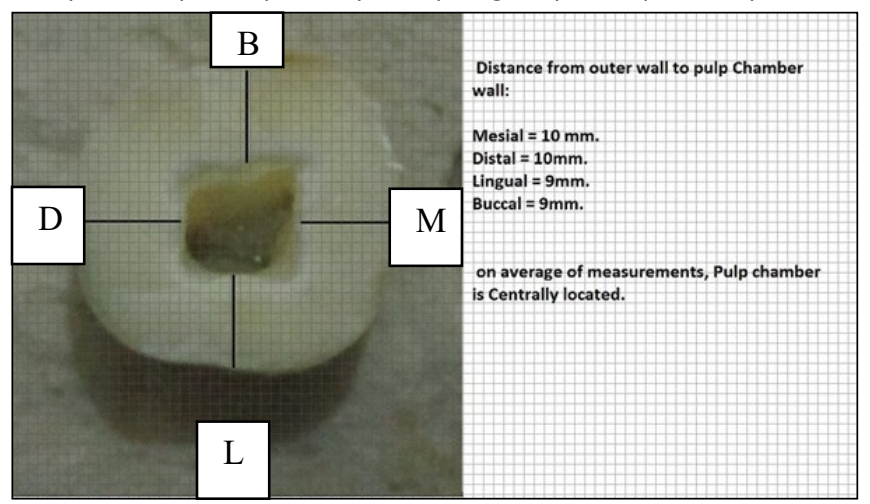

FIGURE II: MESIOBUCCALLY OFF-CENTERED LOCATED PULP CHAMBER

$B^{*}$ (Buccal), $D^{*}$ (Distal), $L^{*}$ (Lingual), $M^{*}$ (Mesial

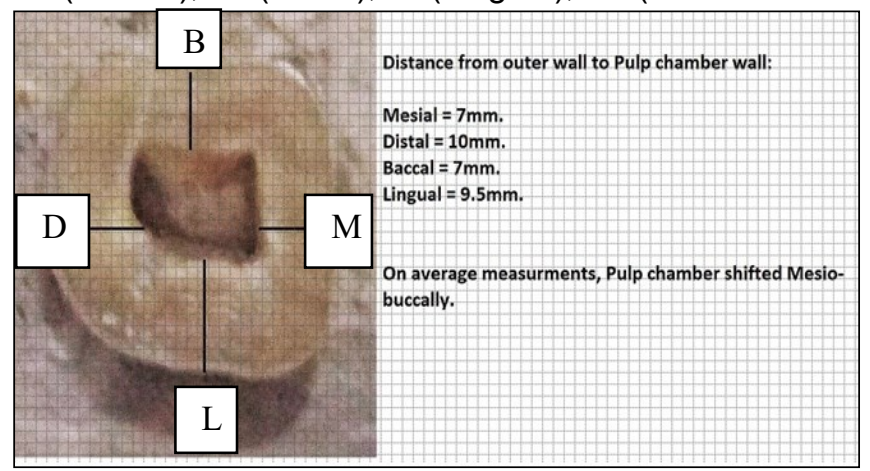

TABLE I: PULP CHAMBER LOCATION

Age Group, Age-group $1=20-40$ years old, Age-group 2 = 41-60 year old

\begin{tabular}{|c|c|c|c|c|}
\hline \multirow{2}{*}{$\begin{array}{c}\text { Pulp chamber } \\
\text { location }\end{array}$} & \multicolumn{2}{|c|}{ Age Groups } & \multirow[t]{2}{*}{ Total } & \multirow[t]{2}{*}{$P$ value } \\
\hline & 1 & 2 & & \\
\hline Centre & $\begin{array}{c}140 \\
(87.5 \%)\end{array}$ & $\begin{array}{c}30 \\
(13.39 \%)\end{array}$ & $\begin{array}{c}170 \\
(41.7 \%)\end{array}$ & \\
\hline $\begin{array}{l}\text { Off center } \\
\text { (mesiobuccaly) }\end{array}$ & $\begin{array}{c}20 \\
(12.5)\end{array}$ & $\begin{array}{c}194 \\
(86.61 \%)\end{array}$ & $\begin{array}{c}214 \\
(58.3 \%)\end{array}$ & 0.001 \\
\hline Total & $\begin{array}{c}160 \\
(41.7 \%)\end{array}$ & $\begin{array}{c}224 \\
(58.3 \%)\end{array}$ & 384 & \\
\hline
\end{tabular}

${ }^{*} P$-value of less than 0.05 was considered statistically significant.

\section{DISCUSSION}

Mandibular first molar (MFM) is the most frequently endodontically treated tooth $^{12,13}$. Literature confirms that there is racial variance in the coronal and radicular morphology of the teeth. Several studies reported number of variables of root canal system of MFM from one population to another ${ }^{3,5,8}$. Study by Walker RT $1988^{14}$ on mandibular molars of Chinese population determined that their population has different root canal system than Caucasian and Africans. Study by Wasti F $2001^{15}$ on South Asians (Pakistani) population reported that root canal system of these populations different from Caucasians. Kim E $2005^{16}$ reported in their study and agreed with the studies by Walker RT $1988^{14}$ and Wasti F $2001^{15}$ and found variations among root lengths of Caucasians and Asians population. Caliskan MK $1995^{17}$ observed permanent teeth in Turkish population and reported variation in root canal configurations from other populations. Gulabivala K $2001^{18}$ evaluated mandibular molars in Burmese population and reported variable root canal configuration. All these studies concluded that both ethnicity origin and gender may be considered before performing endodontic treatment. Akhlaghi NM et al. $^{13}$ also reported variation in root length and number in Iranian population. Ahmed HA $2007^{19}$ studied teeth of Sudanese population and reported different percentage of root canal numbers and configurations than Walker RT $1988^{14}$ and Wasti F $2001^{15}$. In terms of ethnic variance this study is in agreement with the findings of the above studies.

Regarding centered and off centered location of the PC we found $55.7 \%$ of population had mesiobuccally off-centered located pulp chamber, with slight predilection in males for off-center location. Subjects having age range from 41-60 years (Age group 2) had location of pulp chamber off-centered mesiobuccaly considering a significant $p$-value of 0.001 . Results of this study are in contrast to Kransner's law of centrality. Krasner's law of centrality postulates that PC floor is always located centrally at the level of cement enamel junction. They observed 400 extracted teeth to visualize anatomy of teeth, and found PC was centrally placed in their population ${ }^{2}$. Study by Raturi $P$ $2007^{8}$ and others ${ }^{1}$ agreed with findings of Krasner $P$ $2004^{2}$. Findings of this study not consistent with the results of above studies as we found off-centered pulp chamber with slight mesio-buccal extension. Mickel AK $2007^{10}$ concluded in their study on MFM, that PC position at CEJ level is more lingually. This finding is opposite to our results as we noticed mesio-buccal off-center location of PC with computer generated gird and ruler for measurements.

Variable results of this study are partially consistent with earlier studies which reported population variations $^{16,17,20-22}$. In our population sample PC was not always centrally located rather it was found mesiobuccally off-centered (in 55.7\%) at the level of CEJ as shown in Table II. Findings of Gorduysus $O$ 
$2009^{9}$ on mandibular second molars confirm that teeth with three orifices showed slight mesio-buccual inclination. These findings are similar to our observations, but we observed this inclination in MFM. Age related changes also contribute changes in PC morphology. Secondary dentine deposition occurs on the walls and floor of the PC. These changes have direct impact on reduction in volume of pulp space, besides a small gender difference in sizes of pulp volume. Pulp cavity significantly reduces in volume from the age of 22-30 until 51-60 years and no significant changes occur after 61 years of age and this reduction in size occurs mostly in mesial-distal direction $^{4,22-24}$. Result of present study also lies in agreement with previous studies regarding age changes but we have not measured vertical height of the PC separately. Instead of this we relied totally on same methodology of study and found subjects between 41 years to 60 years ages have more mesiobuccal off-centered placed PC at the level of CEJ.

Present study was designed to explore PC morphology in Pakistani population as it was observed over the years clinically by corresponding author that PC in mandibular molars was slightly mesiobuccally off-centered, therefore alternate hypothesis was tested. Traditional endodontic access cavity preparations are more invasive and require removal of sounder tooth structure on lingual side which decreases the fracture resistance of tooth structure and renders it to fracture and ultimately failure of treatment and loss of tooth ${ }^{6}$. According Rahimi S $2008^{25}$ that the conventional notion regarding triangular-shaped access cavity design may not always imitate the anatomy of the pulp chamber floor. Matos $\mathrm{H} 2015^{26}$ concluded that the shape of roots often flattened in the mesiodistal surface in MFM; hence root canals flattened mesiolingually and elongated buccolingually. Contrary to above statement Wilcox LR $1989^{27}$ recommend access preparation of molar teeth should be centered and should not extend to the mesial pit or the mesial marginal ridge. These recommendations may be suitable for the population studied. Text book recommendations ${ }^{1}$ may not be followed for access cavities in posterior teeth as there is no ideal occlusal morphology and underneath identical location of the PC in every patient. Before starting endodontic procedure, the endodontist must consider morphological, racial and hereditary patterns of patients ${ }^{7,28}$. Carrotte P $2004^{29}$ in his clinical demonstration suggested that access cavity represents the shape of the PC, and flared up on to the mesiobuccal portion of the occlusal surface for convenience form, his clinical approach augments the findings of this study. Patel S $2007^{30}$ are also of same opinion that mesio-buccal canal opening is regularly located below the tip of mesio-buccal cusp. Therefore; for predictable results one must consider the morphological dissimilarities of various ethnic groups before the start of endodontic treatment.

\section{CONCLUSION}

The law of centrality says that the floor of pulp chamber always located at the center of tooth at CEJ, but this law is not applicable on every population as shown in our results. We conclude that the pulp chamber in lower first permanent molars is not always positioned at the center of tooth at the level of CEJ but the location of the pulp chamber of mandibular first molar is mesiobuccally off-centered in Pakistani population sample.

Limitations: Our results do not represent all Pakistani population; this study was performed on limited area of local population.

Ethical permission: Liaquat University of Medical \& Health Sciences letter No. AS\&RB-49.10, dated: 1-6-2017.

Conflict of Interest: There is no conflict of interest. Funding: There was no any funding agency.

\section{REFERENCES}

1. Hargreaves KM, Berman LH, Rotstein I. Cohen's Pathways of the Pulp: 11th edition. Publisher; Elsevier Health Sciences Division. 2015.

2. Krasner $P$, Rankow $H J$. Anatomy of the pulp-chamber floor. J Endod. 2004; 30(1): 5-16. doi: 10.1097/00004770-200401000-00002.

3. Margarit R, Andrei OC, Mercut V. Anatomical variation of mandibular second molar and its implications in endodontic treatment. Rom J Morphol Embryol. 2012; 53(2): 413-6.

4. Lokade J, Rawlani S, Baheti R, Roy S, Chandak $M$, Lohe V. Morphological Measurements of Anatomic Landmarks in Human Mandibular Molar Pulp Chambers - An In vivo Study. J Kor Dent Sci. 2011; 4(1): 1-5. doi:10.5856/jkds.2011.4.1.001.

5. Vertucci FJ. Root canal morphology and its relationship to endodontic procedure. Endodc Top. 2005; 10(1): 3-29. doi.10.1111/j.1601-1546. 2005.00129x. 
6. Al Amri MD, Al-Johany $\mathrm{S}$, Sherfudhin $\mathrm{H}, \mathrm{Al}$ Shammari B, Al Mohefer S, Al Saloum M, et al. Fracture resistance of endodontically treated mandibular first molars with conservative access cavity and different restorative techniques: An in-vitro study. Aust Endod J. 2016; 42(3):124-131. doi: 10.1111/aej.12148.

7. McCabe PS. Avoiding perforations in endodontics. J Ir Dent Assoc. 2006; 52(3): 139-48.

8. Raturi P, Girija S, Subash TS, Mangala TM. Unravelling the mysteries of pulp chamber. J Endodontology. 2007; 19: 23-9.

9. Gorduysus O, Nagas E, Cehreli ZC, Gorduysus $M$, Yilmaz Z. Localization of root canal orifices in mandibular second molars in relation to occlusal dimension. Int Endod J. 2009; 42(11): 973-7. doi: 10.1111/j.1365-2591.2009.01596.x.

10. Mickel AK, Chogle S, Bingham R, Self M, Bogle J. A correlation study of occlusal and pulp chamber anatomy: the mandibular first molar. Gen Dent. 2007; 55(3):221-3

11. Goodis CJ. Mandibular Molar Endodontic Treatment: maximizing efficient and safe endodontic therapy. Dent Acad Cont Educ. 2014; Available from: https://dentalacademyofce.com / courses/1458/pdf/mandi_molar_endotrtmnt.pdf.

12. Razmi H, Shokouhinejad N, Hooshyar M. An In Vitro Study of the Number of Distal Roots and Canals in mandibular First Molars in Iranian Population. Iran Endod J. 2008; 2(4): 126-30.

13. Akhlaghi NM, Khalilak Z, Vatanpour M, Muhammadi S, Pirmoradi S, Fazlyab $M$, et al. Root canal anatomy and morphology of first molars in a selected Iranian population: An In vitro study. Iran Endod J. 2017; 12(1): 87-91. doi:10.22037/iej.2017.18.

14. Walker RT. Root form and canal anatomy of mandibular first molars in a southern Chinese population. Endod Dent Traumatol. 1988; 4(1): 19 -22. doi:10.1111/j.1600-9657.1988.tb00287 .x.

15. Wasti F, Shearer AC, Wilson NH. Root canal systems of the mandibular and maxillary first permanent molar teeth of south Asian Pakistanis. Int Endod J. 2001; 34(4): 263-6. doi: 10.1046/ j.1365-2591.2001.00377.x.

16. Kim E, Fallahrastegar A, Hur YY, Jung IY, Kim S, Lee SJ. Difference in root canal length between Asians and Caucasians. Int Endod J. 2005; 38(3): 149-51. doi:10.1111/j.1365-2591.2004.00881.x.

17. Caliskan MK, Pehlivan Y, Sepetcioglu F, Turkun $\mathrm{M}$, Tuncer SS. Root canal morphology of human permanent teeth in a Turkish population. $\mathrm{J}$ Endod. 1995: 21(4): 200-4. doi: 10.1016/S0099-2399(06) 80566-2.

18. Gulabivala K, Aung TH, Alavi A, Ng YL. Root and canal morphology of Burmese mandibular molars. Int Endod J. 2001; 34(5): 359-70. doi: 10.1046/ j.1365-2591.2001.00399.x.

19. Ahmed HA, Abu-bakr NH, Yahia NA, Ibrahim YE, Root and canal morphology of permanent mandibular molars in a Sudanese population. Int Endod J. 2007; 40(10): 766-71. doi: 10.1111/ j.1365-2591.2007.1283.x.

20. Faraz SA, Tariq A, Jameel A. Root canal morphology of mandibular first permanent molar- Karachi sample. Pak Oral Dent J. 2015; 35 (2): 294-8.

21. Martínez-Berna A, Badanelli $P$. Mandibular first molars with six root canals. J Endod. 1985; 11(8): 348-52. 10.1016/S0099-2399(85)80043-1.

22. Srinath S, Somasundaram J. Dimensions of Pulp Chamber and Furcal Dentin in Mandibular First Molar in South Indian Population- A Radiographic Study. J Pharm Sci Res. 2017; 9(7): 1106-7

23. Schroeder HE, Krey G, Preisig E. Age-related changes of the pulpal dentin wall in human front teeth. Schweiz Monatsschr Zahnmed. 1990; 100 (12): 1450-61.

24. Kavas A, Tumen EC. Volumetric pulp chambers measurements in mandibular and maxillary permanent first molar using cone-beam computed tomography by age and gender. Int Dent Res. 2019; 9(1): 30-40. doi:10.5577/intdentres.2019. vol9.no1.5.

25. Rahimi S, Shahi S, Lotfi M, Zand V, Abdolrahimi $M$, Es'haghi R. Root canal configuration and the prevalence of $\mathrm{C}$-shaped canals in mandibular second molars in an Iranian population. J Oral Sci. 2008; 50(1): 9-13. doi: 10.2334/josnusd.50.9.

26. Matos H, Dias A, Matroianni LB, Castiglioni L, Nunes R. Morphology study of mandibular first molars by means of four methods. Dental Press Endod. 2015; 5(1): 55-62. doi:10.14436/21783713.5.1.055-062.oar.

27. Wilcox LR, Walton RE, Case WB. Molar Access: Shape and Outline According to Orifice Locations. J Endod. 1989; 15(7): 315-8. doi: 10.1016/S00992399(89)80054-8.

28. Estrela C, Bueno M, Couto G, Rabelo L, Alencar AH, Silva RG, et al. Study of Root Canal Anatomy in Human Permanent Teeth in A Subpopulation of Brazil's Center Region Using Cone-Beam Com- 
puted Tomography - Part 1. Braz Dent J. 2015; 26 (5): 530-6. doi:10.1590/ 0103-6440201302448.

29. Carrotte P. Endodontics: Part 4 Morphology of the root canal system. Br Dent J. 2004; 197(7): 379383. doi: $10.1038 /$ sj.bdj.4811711.
30. Patel S, Rhodes J. A practical guide to endodontic access cavity preparation in molar teeth. $\mathrm{Br}$ Dent J. 2007 ; 203(3): 133-40. doi: 10.1038/bdj.2007. 682.

AUTHOR AFFILIATION:
Dr. Abdul Qadir Khan Dall (Corresponding Author)
Associate Professor
Department of Operative Dentistry
Liaquat University of Medical and Health Sciences
(LUMHS), Jamshoro, Sindh-Pakistan.
Email: qadir.dall@lumhs.edu.pk
Dr. Sarwanand
Resident, Operative Dentistry
LUMHS, Jamshoro, Sindh-Pakistan.
Dr. Sarwat Batool
Resident, Department of Physiology
LUMHS, Jamshoro, Sindh-Pakistan.
Dr. Suraj Arora
Assistant Professor
Department of Restorative Dental Sciences
College of Dentistry, King Khalid University
Abha, Saudi Arabia.
Dr. Saifullah Qureshi
Senior Dental Surgeon, Operative Dentistry
Govt of Sindh, Karachi, Sindh-Pakistan.
Dr. Muhammad Ahmed Bari
Senior Dental Surgeon, Operative Dentistry
Govt of Sindh, Karachi, Sindh-Pakistan.

